\title{
Epilepsi Cerrahisi Sonrası Geç Başlangıçlı Kleptomani: Bir Olgu Sunumu
}

\author{
Late Onset Kleptomania Following Epilepsy Surgery: A Case Report \\ Pınar Sivrikaya, Çiçek Hocaoğlu \\ Recep Tayyip Erdoğan Üniversitesi, Tip Fakültesi, Psikiyatri Anabilim Dall, Rize, Türkiye
}

\author{
Yazışma Adresi / Correspondence: \\ Çiçek Hocaoğlu \\ Recep Tayyip Erdoğan Üniversitesi Tip Fakültesi Psikiyatri Anabilim Dalı, Rize- Türkiye \\ T: +904642300009 E-mail: cicekh@gmail.com \\ Geliş Tarihi / Received : 28.07.2019 Kabul Tarihi / Accepted : 09.12.2019 \\ Orcid: \\ Çiçek Hocaoğlu https://orcid.org/0000-0001-6613-4317 \\ Pinar Sivrikaya https://orcid.org/0000-0002-4954-5365 \\ ( Sakarya Tip Dergisi / Sakarya Med J 2019, 9(4):725-732) DOI: 10.31832/smj.597729
}

\begin{abstract}
$\ddot{O} z$
Kleptomani, kișisel kullanım ya da parasal değeri için gereksinme duyulmayan nesneleri tekrarlayıcı biçimde çalmaya yönelik dürtülere karșı koyamama olarak tanımlanan bir ruhsal bozukluktur. Kişilerin engelleyemedikleri bu davranışlarından duydukları utanç ve adli hırsızlık vakaları ile karıșmaları sebebiyle yapılan çalışmaların yetersiz olmasından dolayı etiyolojisi, yaygınlı̆̆ ve tedavisine yönelik bilgiler kısıtlldır. Genellikle ergenlik döneminde başlar ve sıklıkla ilerleyen yaşlarda da klinik tablo devam eder. Kleptomani etiyolojisine yönelik olarak psikodinamik yaklaşımlar üzerinde de durulmuștur. Kleptomani duygudurum bozuklukları, obsesif kompulsif bozukluk, madde kötüye kullanımı ile birlikte olabileceği gibi organik beyin patolojilerinde de ortaya çıkabilir. Aynı zamanda epileptik kişilik geliṣtiren bireylerde de kleptomani vakalarına rastlanmışıır. Tedaviye yönelik olarak seçici serotonin gerialım inhibitörleri, duygudurum dengeleyiciler, antipsikotikler, opioid antagonistlerinin kullanıldığı çalışmalar olmakla birlikte, antiepileptiklerin kullanıldığı olgular da bildirilmiștir. Bu çalısmada temporal lob kaynaklı epilepsi nedeniyle, uzun süre antiepileptik kullanımını takiben epilepsi cerrahisi geçiren bir hastada, operasyon sonrası gelişen geç başlangıçlı bir kleptomani tablosu sunulmuştur.

Anahtar Kleptomani; geç bașlangıç; epilepsi; tedavi

kelimeler
\end{abstract}

Abstract

Kleptomania is a psychiatric disorder defined as an inability to resist the impulses to repetitively steal objects that are not needed for personal use or monetary value. As a result of insufficient studies due to embarrassment and confusion with cases of forensic theft, information on the etiology, prevalence, and treatment is limited. It usually begins in adolescence and often continues to develop in later years. Psychodynamic approaches to the etiology of kleptomania are also emphasized. Kleptomania may be associated with mood disorders, obsessive-compulsive disorder, substance abuse, and may occur in organic brain pathologies. There were also cases of kleptomania in individuals who developed an epileptic personality. Although selective serotonin reuptake inhibitors, mood stabilizers, antipsychotics, opioid antagonists have been used for treatment, there have been reported cases where antiepileptics have been used. In this study, a late-onset kleptomania was presented in a patient who had undergone epilepsy surgery following long-term antiepileptic use due to temporal lobe epilepsy.

Keywords Kleptomania; late-onset; epilepsy; treatment 


\section{GİRIŞ}

Kleptomani, kişisel kullanım ya da parasal değeri için gereksinme duyulmayan nesneleri tekrarlayıcı biçimde çalmaya yönelik dürtülere karşı koyamama olarak tanımlanan bir ruhsal bozukluktur. ${ }^{1}$ Tamam’nn bildirdiğine göre; ilk olarak iki yüzyıl önce Matthey, değersiz ve gereksinme duyulmayan nesnelerin dürtüsel biçimde çalınması olarak tanımladığı "klopemanie" terimini kullanmıştır. ${ }^{2}$ Yine aynı çalışmada 1838 yılında Marc ve Esquirol'un, Yunanca "çalma deliliğì" anlamına gelen "kleptomani” terimini kullandıkları, alkolizm, dürtüsel homisid ve yangın çıkarma ile birlikte monomaniler arasında ele alındığı belirtilmiştir. ${ }^{2}$ Kleptomani, 1952 yllında Ruhsal Bozuklukların Tanısal ve İstatistiksel El Kitabı I'de (Diagnostic and Statistical Manual of Mental Disorders - DSM-I) ayrı bir tanı olarak kabul edilmemesine karşın, ek bölüm içinde ele alınmıştır. DSM-II içeriğine ise hiç alınmamıştır. ${ }^{2}$ Daha sonra, DSMIII (APA 1980), DSM-III-R (APA 1987) ve DSM-IV'e (APA 1994) "başka bir yerde sınıflandırılmamış dürtü denetim bozuklukları” başlığı altında incelenmiştir. ${ }^{2}$ Ruhsal Bozuklukların Tanısal ve İstatistiksel El Kitabı̉nın (Amerikan Psikiyatri Birliği 2013) son baskısında (Diagnostic and Statistical Manual for Mental Disorders DSM-5) ise yıkıcı bozukluklar, dürtü denetimi ve davranım bozuklukları kategorisinde yer almıştır. ${ }^{3}$ Çalışmaların yetersizliği nedeni ile kleptomaninin epidemiyolojisi ile ilgili bilgiler son derece sınırlıdır. Genel nüfus içinde her 1000 kişiden 5'inin kleptomanik olduğu tahmin edilmektedir. ${ }^{4}$ Ancak, bu verilerin kleptomaninin gerçek sıklığını göstermediği, gerçek sayıların daha fazla olduğu düşünülmektedir. Kleptomanili hastaların klinik özelliklerinin araştırıldığ çalışmalarda hastaların çoğunlukla kadın cinsiyet olduğu bildirilmiştir. Bu bozukluk genellikle ergenlik döneminde başlar ve geç erişkinliğe kadar sürer, bazı hastalarda ömür boyu sürebilir., ${ }^{1,4}$ Engellenemeyen çalma dürtüsü yakınması ile hekime başvuru sayısı hastaların bu durumdan utanmaları nedeni ile yok denecek kadar azdır. Ayrıca, başka yakınmalarla başvuran hastalarda eş tanı olarak kleptomani tanısı konulabilmektedir. ${ }^{5,6}$
Kleptomaninin etiyolojisini açıllamaya yönelik hem psikolojik hem de biyolojik hipotezler ortaya atılmış, çeşitli psikiyatrik bozukluk spektrumlarının içerisinde yer aldığ düşünülmüş ve semptomatolojisi nedeni ile psikiyatrik bozukluklarla ilişkilendirilmiştir. ${ }^{7}$ Nörolojik ve bilişsel bozukluklar davranış kontrolünü etkileyebilir ve toplumsal kabulün dışına taşan davranış profillerine yol açabilirler. Orbitofrontal korteks, dorsolateral prefrontal korteks ve anterior singulat girus bölgelerinin dürtüsel davranış gelişiminde rol oynadıkları düşünülmektedir. ${ }^{7}$ Kleptomani hastalarında difüzyon tensor görüntüleme yöntemi ile yapılan bir çalışmada diğer dürtü denetim bozuklukları ile yapılan çalışmalarla uyumlu olarak inferior frontal bölgelerde beyaz cevher mikroyapisında entegrasyon azalması ortaya konmuştur ve bu bölgenin kleptomani etiyolojisindeki olası rolüne dikkat çekilmiștir. ${ }^{8}$ Nörolojik klinik görünümler ile kleptomani ilişkisini gösteren bir olgu sunumu çalışmasında sol temporal lob epilepsisi ile kleptomaninin eş zamanlı başladığı ve topiramat tedavisi ile kleptomani belirtilerinin düzeldiği bildirilmiştir. ${ }^{9}$ Kleptomaninin diğer dürtü denetim bozukluklarına benzer şekilde duygudurum bozuklukları ile ortak özellikler gösterdiği, beyinde düşük serotonin düzeyleri gibi biyolojik benzerlikleri ve nörokimyasal bozuklukları paylaştı̆̆ı ileri sürülmüştür. ${ }^{10}$ Bugüne kadar kleptomaninin epidemiyolojisi, etiyolojisi, klinik seyri, tedavi yaklaşımları ile diğer psikiyatrik ve nörolojik hastalıklarla ilişkisi tam olarak açıklanamamıştır. Bu yazıda temporal lob kaynaklı epilepsi nedeniyle, uzun süre antiepileptik kullanımını takiben epilepsi cerrahisi geçiren bir hastada, operasyon sonrası gelişen geç başlangıçlı bir kleptomani olgusu tanı ve tedavi yaklaşımları mevcut literatür bulguları eşliğinde tartışılarak, literatüre katkı sağlanması amaçlanmıştır.

\section{OLGU SUNUMU}

Kırk yaşında, erkek, ilkokul mezunu, aşçı, evli, üç çocuk babası hasta ayaktan tedavi birimimize moralsizlik, iş yapamama, isteksizlik, keyifsizlik, unutkanlık, iç sıkıntısı, takıntılı düşüncelerden kurtulamama, uykusuzluk yakınmaları ile başvurdu. 
İlk başvurusu sırasındaki psikiyatrik değerlendirme sonucu DSM-5'e göre obsesif kompulsif bozukluk (OKB) ve major depresif bozukluk (MDB) tanıları ile essitalopram 10 mg/gün tedavisi başlanan hasta kontrole çağırıldı. İkinci görüşmede ise, 'çok utanç verici bir durum yaşadığını, bunu kimse ile paylaşamadığını' belirterek hekimine 'kendini kontrol edemediği çalma davranışı' olduğunu ifade eden hastanın bu yakınmasının 4 yıl önce geçirdiği epilepsi cerrahisinden 6 ay sonra bir alışveriş merkezinde dolaşırken rafta gördüğü bir parfümü gizlice alması ile başladığı öğrenildi. Hastamız; bu parfüme hiç ihtiyacı olmadığını, parfümü alabilecek parası olduğunu, fakat o an parfümü gizlice almak için çok yoğun bir istek duyduğunu, kendisini durduramadığını, parfümü gizlice almaktan başka ihtimal yokmuş gibi hissettiğini belirtti. Parfümü aldığı anda rahatlama hissi ve haz duymasına rağmen, mağazadan çıktıktan bir süre sonra çok pişman olduğunu, ihtiyacı olmamasına ve alacak parası olmasına rağmen neden çalma arzusunun olduğuna bir anlam veremediğini ve parfümü attığını, sonrasında o mağazaya tekrar giderek yerde bulmuş gibi yaptığı bir miktar parayı kasaya teslim ettiğini söyledi. Sonrasında bu isteğinin 3-4 günde bir tekrarladığını, kendisini engelleyememekten korktuğu için özellikle çalma isteğinin arttığı büyük alışveriş merkezlerine gitmekten vazgeçtiğini, kendisine giyecek kıyafet almaya bile gitmekten çekindiğini, eşinden kendisine giysi almasını istediğini belirtti. Hasta yaptığının yanlış olduğunu bildiğini ve bundan dolayı suçluluk, utanç duyduğunu, son aylarda içe kapanma, durgunluk, işe gitmek istememe, takıntılı düşünceler, moralsizlik, keyifsizlik yakınmalarının olduğunu ve giderek arttığını anlattı.

Özgeçmiş: Dört çocuklu bir ailenin ikinci çocuğu olarak doğan hastanın çocukluk dönemi köyde, tutucu ve baskıcı bir ortamda geçmiş. Annesini çekingen, iyimser bir insan olarak tanımlayan hasta, babasını ise, baskıcı, titiz, kendi kurallarına bağlı, sert mizaç özelliklerine sahip bir kişi olarak tanımladı. Anne ve babası amca çocuklarıymış ve kaçarak evlenmişler. Hastamız ve kardeşleri babaların- dan çok korkarmış, annelerine ve kendilerine karşı bazen haftada 3 gün fiziksel şiddet gösterdiği olurmuş. Anne ve babası genel olarak iyi geçinemezlermiş, evde sık sık küslüğün yaşandığı, kavgalı bir ortam olurmuş. Hasta Babasının zaman zaman alkol aldığını belirtti. Babası hayvancılık ile uğraşıyormuş, geçim sıkıntıları olmamış. Fakat ihtiyaçlarını dile getirmekten her zaman çekinirlermiş. Babaları bu konuda çok sert davranırmış, ondan korktukları için ihtiyaçları olduğu halde aldıkları en ufak eşyayı bile göstermekten çekinirlermiş. Şu an anne ve baba hayatta, her ikisi de 65 yaşında, babasının baskıcı tavrının halen devam ettiğini belirtiyor. Hastamızın kendisinden büyük bir ağabeyi ile kendisinden küçük iki erkek kardeşi var. Kardeşleri ile arası son döneme kadar iyiymiş. Ancak, son dönemde anne babasından kaynaklı aralarının bozulduğunu ifade ediyor. Ailesinin çocukları arasında ayrım yaptığını, en büyük ve en küçük kardeşlere daha yoğun ilgi gösterdiklerini ve daha çok destek olduklarını düşünüyor. Son dönemde kardeşleri ile birlikte işlettikleri lokantadan anne ve babasının taraflı tutum ve davranışlarından dolayı ayrıldığını belirtti.

Evde, köy ebesinin yardımı ile dünyaya gelmiş, annesi ikinci bebeğine çok erken gebe kaldığı için korkusundan gebeliğini çok uzun süre kayınpederinden gizlemiş. Hastamız doğduktan 6 ay sonra ateşli havale geçirmiş, aile büyükleri doktora götürmek istememiş, annesi havale sonrasında 2 gün süreyle bir tarafındaki kol ve bacağını hiç oynatamadığını söylermiş. Tuvalet alışkanlığını zamanında kazanmış, çocukken idrar kaçırma öyküsü yok. Zamanında konuşmuş fakat geç yürümüş. Dokuz yaşından bu yana el tırnaklarını yeme huyu mevcut. Babasından korktuğu için yaramazlık yapmaktan çekinirmiş. Okula 7 yaşında köy ilkokulunda başlamış. Okulu hiç sevmemiş, dersleri iyi değilmiş. Ancak, okulda öğretmenlerine karşı saygısızlığı, kural dışı davranışı olmadığını belirtti. Arkadaşları ile uyumluymuş. Ergenlik dönemini de sakin geçirmiş. Epilepsi hastalığı ilk kez 17 yaşındayken dilinde konuşurken pelteklik olması ile başlamış. Hasta olmadan önce hasta 
ve nöbet geçiren insanlardan çok korkarmış, hasta olunca kendi hastalığından da çok korktuğunu belirtiyor. Sürekli ilaç kullanacak olmaktan da korkmuş. Konuşmasındaki problem ilaç tedavisine başladıktan sonra düzelmiş. Hastamız temporal lob epilepsi nedeniyle 22 yıl süreyle tedavi gördüğünü belirtti. Bilinç kaybının eşlik ettiği, günde 2-3 kez tekrarlayan özellikle gece uykuda başlayan jeneralize tonik klonik nöbetleri olduğu, bu sebeple çok sayıda antiepileptik ilaç kullandığı fakat çoğundan fayda göremediği, özellikle karbamazepin tedavisinden fayda gördüğü öğrenildi. Hastamızın bu dönemde epilepsi hastalığının hayat kalitesini bozmasından kaynaklı depresif dönemleri olmuş ve farklı dönemlerde paroksetin, sitalopram gibi antidepresan ilaç tedavileri kullanmış. Antiepileptik ilaç tedavisine rağmen tekrarlayan dirençli nöbetleri olması nedeniyle yaşam kalitesinin oldukça etkilendiğini söyleyen hasta, Ekim 2014'te bu nedenle ameliyat olduğunu belirtti. Ameliyat sonrası dönemde herhangi bir komplikasyon gelişmemiş. Fakat ameliyattan 10 gün sonra iç sıkıntısı, çarpıntı, iştahsızlık yakınmaları ve epilepsi hastalığının iyileşemeyeceği, ameliyattan da fayda göremeyeceği yönünde düşünceleri olmuş. Bu nedenle hastaya ismini bilmediği antidepresan ilaç tedavisi başlanmış. Ameliyat sonrası tekrar epilepsi nöbeti geçirmeyen hastanın, bir akşam evde yemek yerken aniden gelişen boğulur gibi hissetme şikayeti olmuş. Ardından bayıldığını tarifleyen hasta, bu sırada çevrede konuşulanları duyduğunu fakat yanıt veremediğini belirtti.

Askere 3 ay süreyle gittiğini, fakat sonrasında hastalığı dolayısıyla askerliğini yapamaz diye askerliğe elverişsiz raporu verildiğini, bu durumun kendisini çok üzdügünü, 'eksik kalmış hissettirdiğini' belirtti.

Eşiyle 22 yıl önce kaçarak evlenmişler, o dönemde kendisinin bir iş ve geliri yokmuş. Babası başta çok kızmış, fakat sonradan destek olmuş. Evleri olmadığı için ilk başta ailesi ile yaşamışlar, sonraki yıllarda kendi evleri olmuş. Eşi 40 yaşında, ev hanımı. Hastamız eşinin uyumlu ve iyi bir insan olduğunu kendisini çok idare ettiğini, evde kavga etme huylarının olmadığını belirtiyor. İki kız, 1 erkek 3 çocukları var. Hastanın çocukları ile ilişkisi iyi, çocuklarını sıkma- dığını, okumalarına önem verdiğini belirtti.

Sigara, alkol ve madde kullanım öyküsü yok. Ancak son yıllarda bilgisayar oyunları ve sosyal medya kullanımına olan ilgisi artmış. Kahvehane ortamına ancak arkadaşları ile sohbet etmek için gidermiş. Özellikle gezmekten, spor ve yürüyüş yapmaktan keyif alıyormuş. Bir an aklına estiğinde alıp başını yaylaya ya da gezmeye gitmekten çok hoşlandığını ifade ediyor. Şu an gelir düzeyi orta/iyi seviyedeymiş.

Antiepileptik ilaç tedavisi, ameliyat sonrası bir buçuk yıl daha devam etmiş ve azaltılarak kesilmiş. Ameliyat öncesi $118 \mathrm{~kg}$ olan hasta, ameliyat sonrası kendi isteği ile $40 \mathrm{~kg}$ vermiş ve özbakımı artmış. Ailede dayısında da epilepsi öyküsü mevcut. Bunun dişında ailede bilinen psikiyatrik ve hastalık öyküsü tanımlanmadı.

Fizik Muayene ve Laboratuar Bulguları: Nörolojik ve diğer sistem muayenelerinde herhangi bir patolojik bulgu saptanmadi. Tiroid fonksiyon testleri, vitamin B12, folik asit, hemogram ve biyokimyasal değerleri normal olarak değerlendirildi.

Elektroensefalografi (EEG): Serebral biyoelektrik aktivitenin normal sinırlarda uyanıklık ritmi ile uyumlu olarak rapor edildi.

Kontrastlı Kranial MR İncelemesi: 'Beyin sap1, her iki serebellar ile 4. ventrikül genişliği doğaldır. Üçüncü lateral ventriküllerin genişliği normaldir. Periventriküler ve supraventriküler beyaz cevher alanları doğaldır. Sağ frontoparietal bölge ekstra-aksiel beyin - omurilik sıvısı (BOS) mesafesinde sağ parankime hafif bası oluşturan yaklaşık $5 \times 1,5 \mathrm{~cm}$ boyutlu T2 ve FLAİR'de hafif hipertens, T1A'da hipotens sinyal özelliğinde; intravenöz kontrast madde (İVKM) enjeksiyonu sonrası periferik kontrastlanma gösteren koleksiyon dikkati çekmektedir (hematom? abse?). Bu seviyede ayrıca kraniotomi defekti izlenmektedir. Sağ temporal lob inferiorunda geçirilmiş hadiseye sekonder 
fokal ensefalomalazi alanı ve perifokal gliozis mevcuttur. Bu seviyede parankimal patolojik kontrast tutulumu saptanmadı. Dural minimal kontrastlanma izlenmektedir. Bilateral talamus, kapsülla interna, eksterna ile bazal ganglionlar doğaldır. Her iki sentrum semiovale doğaldır. İntrakranial yer kaplayan kitle ya da kanama bulgusu yoktur. Herniasyon ya da şift yoktur. Kemiklerde litik ya da destrüktif lezyon yoktur.' şeklinde raporlandı.

Ruhsal Durum Muayenesi: Yaşında gösteren, kılık kıyafeti sosyoekonomik düzeyiyle uyumlu erkek hasta, kendine bakımı iyi düzeyde. Göz teması kuruyor. Konuşması açık, akıc1, anlaşılır, amaca yönelik, ses volümü normal düzeydeydi. Affekti anksiyöz, duygudurum elemli. Zeka düzeyi yaşı ve sosyokültürel düzeyi ile uyumlu. Algılamada psikopatolojik bulgu yok. Bellek fonksiyonu korunmuş. Gerçeği değerlendirme yetisinde ve yargılamada psikopatolojik bir bulgu gözlenmedi. Çağrışımları düzenli, düşünce içeriğinde kleptomani ile ilgili düşünceleri, bu davranışından dolayı suçluluk ve pişmanlık duyması, eşi dahil olmak üzere herkesten gizlediği bu durumun duyulması ile ilgili taşıdığ1 endişe, değersizlik düşünceleri mevcuttu. Benlik saygısı azalmıştı.

Psikometrik Değerlendirme: Yale Brown Obsesyon Kompulsiyon Ölçeği'nden (Y-BOCS) özellikle simetri, şüphe olmak üzere 36 puan, Hamilton Depresyon Değerlendirme Ölçeği'nden 21 puan, Barratt Dürtüsellik Ölçeği Kısa Formu'dan 72 puan almıştır. Minnesota Çok Yönlü Kişilik Envanteri (MMPI) ise zayıf kendilik değeri olan, kendisinden memnun olmayan, durumunu değiştirecek beceri ve nitelikten yoksun olan bir birey olabilir; şeklinde raporlanmıştır.

Klinik Seyir: Psikiyatrik değerlendirme sonrası hastaya, DSM-5’e göre MDB, OKB ve kleptomani tanısı konuldu. Hastaya ilk başvurusunda başlanan essitalopram dozu 20 mg/gün olarak arttırıldı. Eş zamanlı olarak bilişsel-davranışçı terapi (BDT) uygulamalarına yer verildi. BDT süreci değerlendirme ve vaka formülasyonu ile başlamış, daha sonra OKB tanısına yönelik BDT modelini içeren psikoeğitim yapılmış, hastanın belirti ve bulguları bu bağlamda değerlendirilmiştir. Mevcut yorumları ile ilgili bilişsel yeniden yapılandırma teknikleri uygulanarak, maruz b1rakma ve yanıt önleme tedavisinin (Exposure-Response Prevention-ERP) rasyoneli aktarılmıştır Tedavisinin ikinci ayında kleptomani yakınmasının kaybolduğu ve kendisine sıkıntı veren düşüncelerden uzaklaştığı saptanmış olup, halen mevcut tedavisi devam etmektedir.

\section{TARTIŞMA}

Tarihin eski dönemlerinden bu yana kleptomani tanımlanmasına karşın, bu bozukluğa ilişkin oluş nedenleri, yaygınlığ 1 ve tedavisi ile ilgili çok az şey bilinmektedir. ${ }^{1,3}$ Önceki çalışmalara ve literatür taramasına dayanarak, kleptomaninin olası nedenleri arasında; genetik faktörler, ailesel faktörler, kişilik bozuklukları, sosyal faktörler, biyolojik faktörler sayılabilir., ${ }^{2,8}$ Kleptomani hastalarının çoğunda birinci derece akrabalarında kleptomani öyküsü mevcuttur. ${ }^{2}$ Bizim olgumuzda birinci derece yakınlarına ilişkin kleptomani veya psikiyatrik hastalık öyküsü tanımlanmamıştır. Fakat kleptomani açısından daha öncede belirtildiği üzere kişiler utanç duydukları bu durumu gizleme eğilimindedir. Olgumuz da hastalığını eşi dahil olmak üzere tüm yakınlarından gizlemekteydi. Bu açıdan değerlendirildiğinde kişinin de ailesinde mevcut bir başka kleptomani hastasından haberdar olmayabilir.

Psikodinamik açıdan hastaların çoğunun nahoş ya da anormal çocukluk deneyimleri yaşadığına inanılmaktadır ve bu zorlayıcı çalma dürtüsünün, çocukluklarındaki kayıp duygusunu telafi etme amacı taşıdı̆̆ı düşünülmektedir. ${ }^{7,10}$ Olgumuzun aile ve çocukluk öyküsünde baskıcı ve muhafazakâr, kapalı bir çevrede yetiştiği, özellikle babasına karşı yoğun korku içerikli duyguları olduğu, ihtiyaçları konusunda dahi kısıtlandığı, şiddete maruz kaldığı, bu sebeple çocukken arkadaşları ile vakit geçirirken bile yaramazlık yapmaktan çekinme eğilimde olduğu öğrenildi. Bu bulgular mevcut çalışmaların sonuçları ile uyumludur. Kişilik özellikleri açısından bakıldığında kleptomani ta- 
nılı olgularda iki kişilik teorisinden söz edilmiştir. ${ }^{2,7}$ İlki kendini genişletme (self-expansion) eğiliminde olmadır. $\mathrm{Bu}$ insanlar empati duymazlar ve başkalarının duygularını önemsemeden yapmak istediklerini yaparlar. Diğer özellik ise kendini baskılamadır. Bu tip kleptomanik insanlar; insanlara karşı çok kayıtsız, nadiren başkalarıyla etkileşime giren, özgüven ya da öz saygı duymayan ve kendi duygusal ihtiyaçları çocuklukta tatmin edilmemiş bireylerdir. Hastaların kişilik özellikleri hastalığın temelini oluşturur ve çevresel uyaranlar hastalığın tetikleyicileri olarak görev yapar.10 Hastamızın MMPI sonucunda da zayıf kendilik değeri olan, kendisinden memnun olmayan diğer kişiler tarafından uzak ve anlaşılmaz olarak tanımlanabilen, derin duygusal ilişkiden çekinen bir birey olabileceği açıklanmıştır. Yine Barratt Dürtüsellik Ölçeği'ne göre de yüksek puan alan hastamızın geçmiş yaşam öyküsü incelendiğinde, henüz yeterli ekonomik geliri olmamasına rağmen eşini kaçırarak evlenmesi, ailesinin kendisini anlamadığı belirterek ortak çalıştırdıkları iş yerinden ani bir kararla ayrılması dürtüsellik yönünün olduğunu destekler niteliktedir.

Kleptomani tanılı hastalar sık olarak stresli yaşam olayları ile karşı karşıya kalabilir. Stres, depresyon, anksiyete gibi olumsuz duygulara karşılık uygun bir yasal çıkış yolu bulamazlar ve bastırılmış dürtüleri artar, bunun sonucunda da rahatlamaya yönelik yasal olmayan bu tip davranışlar ortaya çıkabilir. ${ }^{2}$ Kleptomani tanılı kişiler için, çalma davranış1 zorunlu ve heyecan vericidir, çalma sonucu elde edilen başarı anormal memnuniyetle karşılanır ve başarı duygusunu tatmin edebilir. Elde edilen bu tatmin duygusundan hareketle, kleptomani ile sonuçlanan hırsızlığı kontrolsüz bir şekilde tekrarlarlar. ${ }^{10}$ Olgumuzda da benzer şekilde özellikle sıkıntılı olduğu dönemlerde çalma davranışı sırasında kendisi için odaklandığı nesneyi çalmaktan başka bir alternatifi olmadığını düşündüğünü aynı zamanda çok yoğun bir rahatlama ve haz duyduğunu ifade edilmiş olması bu sonuçlarla uyumludur.

Bedensel hastalıklar incelendiğinde; çalışmalar, kompulsif hırsızlığa tümör, epilepsi, mental retardasyon, demans veya ilaca bağlı değişiklikler gibi bazı tıbbi etmenlerin neden olabileceğini göstermiştir. ${ }^{6,8,11}$ Kleptomani tanılı çocukların beyinlerinde displazi veya anormal monoamin metabolizması olabilir. Bu çocukların duygusal kipleri ve davranışları akranlarından farklıdır. Beynin fizyolojik fonksiyonuna göre, hastalığın beynin limbik sisteminde var olabileceği, arzu edilen dürtünün artması ve beyin korteksinin kontrol fonksiyonunun bozulmasina neden olacağ1 tahmin edilmektedir. ${ }^{12}$ Olgumuzun tıbbi öyküsünde 17 yaşından itibaren temporal lob epilepsisi nedeniyle dirençli nöbetler geçirdiği ve antipileptik ilaç tedavisi kullandığı, dirençli nöbetlerinin kontrol altına alınamaması nedeniyle de epilepsi cerrahisi geçirdiği öğrenilmiştir. Epilepsi tanısı ile izlenen olgularda genel toplumdan daha yüksek oranda psikiyatrik bozukluklara sahiptir. En sık gözlenen psikiyatrik bozukluklar, anksiyete bozuklukları ve duygudurum bozukluklarıdır. ${ }^{13}$ Temporal lob kaynaklı karmaşık parsiyel nöbetlere (complex partial seizures- CPSs) interiktal duygudurum bozuklukları, dürtü kontrol bozuklukları, kaygı ve saldırganlık eşlik edebilir. ${ }^{14}$ Emosyonların düzenlenmesinde, davranışsal ve dürtü kontrolünde önemli fonksiyonel rollere sahip amigdala, epilepsili olguların hem nöbet aktivitesine hem de psikopatolojiye katkıda bulunan ortak biyolojik mekanizmalar ile nöronal uyarılabilirliği arttırabilir. Ayrıca, epileptik hipereksitabilite üreten amigdaladaki hücresel ve moleküler mekanizmalar, uygun olmayan saldırganlık ve dürtü kontrolü eksikliği gibi duygusal işlev bozukluğuna da neden olabilir. ${ }^{11}$ Olgumuz epilepsi nöbetleri geçirdiği dönemde kleptomani tanımlamamıştır. Ancak, bu dönemde hastamız karbamazepin başta olmak üzere pek çok farklı antiepileptik ilaç kullanmaktaydı. Diğer tedavilere kötü yanıt veren ve tek başına veya serotonin geri alım inhibitörleri (SSGI) ile kombinasyon halinde topiramat tedavisi ile düzelen üç kleptomani olgusunu içeren çalışma bu sonuçları destekler niteliktedir.' Ancak, dürtü kontrol bozukluklarının tedavisinde kullanılan bir başka duygudurum dengeleyici olarak karbamazepin ile klomipramin birlikte kullanımında kleptomani belirtilerinin düzelmediğini belirten çalışmalar da dikkat çekicidir. ${ }^{15}$ Kleptomani genellikle geç ergenlik döneminde başlayan 
ve uzun yıllar devam eden bir bozukluktur. Bu bilgiler 1şığında bakıldığında, olgumuzda kliniğin geç başlangıçlı olduğu izlenmektedir. Geç başlangıçlı bu tabloda tetikleyici etkenler düşünüldüğünde, hastanın daha önce de dürtüsel kişilik yapısına bağlı olarak kleptomani belirtileri sergileyebileceği ve fakat mevcut antiepileptik kullanım öyküsü nedeniyle belirtilerin baskılandığg, ilaç tedavisinin tedricen azaltılarak kesilmesini takiben kliniğin semptomatik hale geldiği de düşünülebilir. Epileptik kişilik geliştiren olgularda kleptomaniye rastlanıldığını bildirmiştir. ${ }^{19}$ Bir başka açıdan değerlendirildiğinde ise, kleptomaninin epilepsi cerrahisine ikincil, cerrahi sonrası gelişip gelişmediğini açıklayabilecek kanıt ve kaynak bulunamamıştır. Fakat, operasyon sonrası dönemde hastanın yaşamış olduğu stresin kleptomani belirtilerinin ortaya çıkmasına zemin hazırlamış olabileceği düşünülebilir.

Kleptomani hastalarında eşlik tanılı OKB, duygudurum bozuklukları, anksiyete bozuklukları, yeme bozuklukları, kişilik bozukluğu ve madde bağımlılı̆̆ı görülme oranları yüksektir. ${ }^{2}$ Özellikle çalma dürtüsünün anlamsız, saçma ve gerginlikle ilişkili bulunması nedeni ile kleptomani, obsesif kompulsif bozukluğun obsesyonları ile benzeşmektedir. Pek çok kleptomani tanılı hastada sık ve aşırı el yıkama, biriktirme, kompulsif satın alma bozukluğu gibi obsesif kompulsif bozuklukla ilişkili özellikler izlenmektedir., ${ }^{1,2}$ Çalışmamızda benzer şekilde olgumuzun kleptomani ile eştanılı major depresif bozukluk ve OKB tanılarının bulunması mevcut literatür bulguları ile uyumludur. Kleptomani ve obsesif kompulsif bozukluğun benzer klinik görünümlerinin yanı sıra ortak bir etiyolojiye de sahip olabileceklerini düşündürmektedir. Ayrıca, her iki ruhsal bozukluğun tedavisinde benzer şekilde yüksek doz SSGI türü antidepresan ilaçların kullanılması ve tedavi sonucu belirtilerin kaybolması da dikkat çekicidir. Kleptomani tedavisi konusunda yeterince çalışma bulunmamaktadır. Geniș bir spektrumda tedavi stratejileri örneğin psikoanalitik yönelimli psikoterapiler, davranışçı tedaviler ve farmakoterapiler gibi yaklaşımlar önerilmiștir. Kleptomani tanılı hastalarının tedavisinde SSGI, duygudurum düzenleyicileri ve opioid antagonistleri gibi ilaçlar kullanılmaktadır. ${ }^{16,17} \mathrm{Bu}$ çalışmalarla benzer şekilde olgumuzun tedavisi için bir SSGI olan essitalopram tercih edilmiştir. Essitalopram $20 \mathrm{mg} /$ gün tedavisi sonrası hastanın çalma davranışının tekrarlamadığını öğrenilmiştir. Bu durum daha önce bildirilen vaka ve tedavi yaklaşımları ile benzerlik göstermektedir. Kleptomaninin spontan remisyon oranı ve uzun dönem prognoz ile ilgili yeterli veri bulunmamaktadır. Ayrıca, nörolojik hastalıklar ile kleptomani ilişkisi de tam olarak bilinmemektedir. Bugüne kadar yapılan çalışmalarda epilepsi ile kleptomani arasındaki ilişkiye dikkat çekilmiş. Ancak, bu ilişkinin nasıl ve neden ortaya çıktığı yeterince aydınlatılamamıştır. Olgumuz epilepsi cerrahisi sonrası geç yaşta başlayan bir kleptomani vakası olması yönünden önemlidir.

Sonuç olarak, kişinin yaşamını olumsuz yönde etkileyen ve depresif belirtiler ile birliktelik gösterebilen, özellikle geç başlangıçlı kleptomaninin tıbbi nedenlerinin daha iyi açıklanabilmesine ihtiyaç vardır. Bu nedenlerin daha iyi anlaşılması tedavi yaklaşımına da yön verebilir. Çalışmamızın bu yönü ile mevcut yazına katkı sağlayacağı inancindayı.

Bu çalışma ile ilgili herhangi bir çıkar çatışması ve finansal destek mevcut değildir. 
Sakarya Tip Dergisi 2019;9(4):725-732

siVRIKAYA ve Ark., Geç Bașlangıçlı Kleptomani: Bir Olgu Sunumu

\section{Kaynaklar}

1. Hocaoğlu C, Tosun AF. A little known topic 'Kleptomania': A case report. Klinik Tip Bilimleri Dergisi 2018; 6(2):21-25.

2. Tamam L: Dürtü Kontrol Bozuklukları. Ankara: Hekimler Yayın Birlĭ̆i, 2009.

3. Association AP. Diagnostic and Statistical Manual of Mental Disorders. Arlington: VA: American Psychiatric Association; 2013.

4. Sipowicz J, Kujawski R. Kleptomania or common theft - diagnostic and judicial difficulties. Psychiatr Pol 2018;52(1):81-92

5. Blum AW, Odlaug BL, Redden SA, Grant JE. Stealing behavior and impulsivity in individuals with kleptomania who have been arrested for shoplifting. Compr Psychiatry 2018;80:186-191.

6. Birkhoff JM, Garberi $C, \operatorname{Re} L$. The behavioral variant of frontotemporal dementia: An analysis of the literature and a case report. Int J Law Psychiatry 2016;47:157-163.

7. Zhang ZH, Huang FR, Liu DH. Kleptomania: Recent advances in symptoms, etiology and treatment. Curr Med Sci 2018;38(5):937-940.

8. Grant JE, Correia S, Brennan-Krohn T. White matter integrity in kleptomania: a pilot study. Psychiatry Res 2006;147(2-3):233-237.

9. Dannon PN. Topiramate for the treatment of kleptomania: a case series and review of the literature. Clin Neuropharmacol 2003;26(1):1-4.

10. Baylé FJ, Caci H, Millet B, Richa S, Olié JP. Psychopathology and comorbidity of psychiatric disorders in patients with kleptomania. Am J Psychiatry 2003;160(8):1509-1513.
11. Kaplan Y. Epilepsy and kleptomania. Epilepsy Behav 2007;11(3):474-475.

12. Hergüner S, Tanidir C. An adolescent with kleptomania and attention-deficit/hyperactivity disorder treated with methylphenidate. J Child Adolesc Psychopharmacol 2011;21(4):383384.

13. Kuladee S, Prachason T, Srisopit P, Trakulchang D, Boongird A, Wisajan P et al. Prevalence of psychiatric disorders in Thai patients with epilepsy. Epilepsy Behav 2019;90(3):20-24.

14. Yang $W$, Chen $C, W u B$, Yang $Q$, Tong $D$. Comprehensive analysis of presurgical factorspredicting psychiatric disorders in patients with refractory temporal lobe epilepsy and mesial temporal sclerosis underwent cortico-amygdalohippocampectomy. J Clin Lab Anal 2019;33(3):e22724.

15. Baltacıoğlu M, Eşsizoğlu A, Yenilmez Ç, Kaptanoğlu C. Kleptomanide ayırııı tanı ve psikodinamik yaklaşım: bir olgu sunumu. Düşünen Adam The Journal of Psychiatry and Neurological Sciences 2015;28(2):66-72

16. Grant JE, Odlaug BL. Kleptomania: clinical characteristics and treatment. Braz J Psychiatry 2008;30 Suppl 1:11-15.

17. Calıyurt O, Tamam L. Kleptomanide tedavi seçenekleri. Güncel Yaklaşımlar-Current Approaches in Psychiatry 2009; 1:1-10. 